What do science teachers find most satisfying about their work?

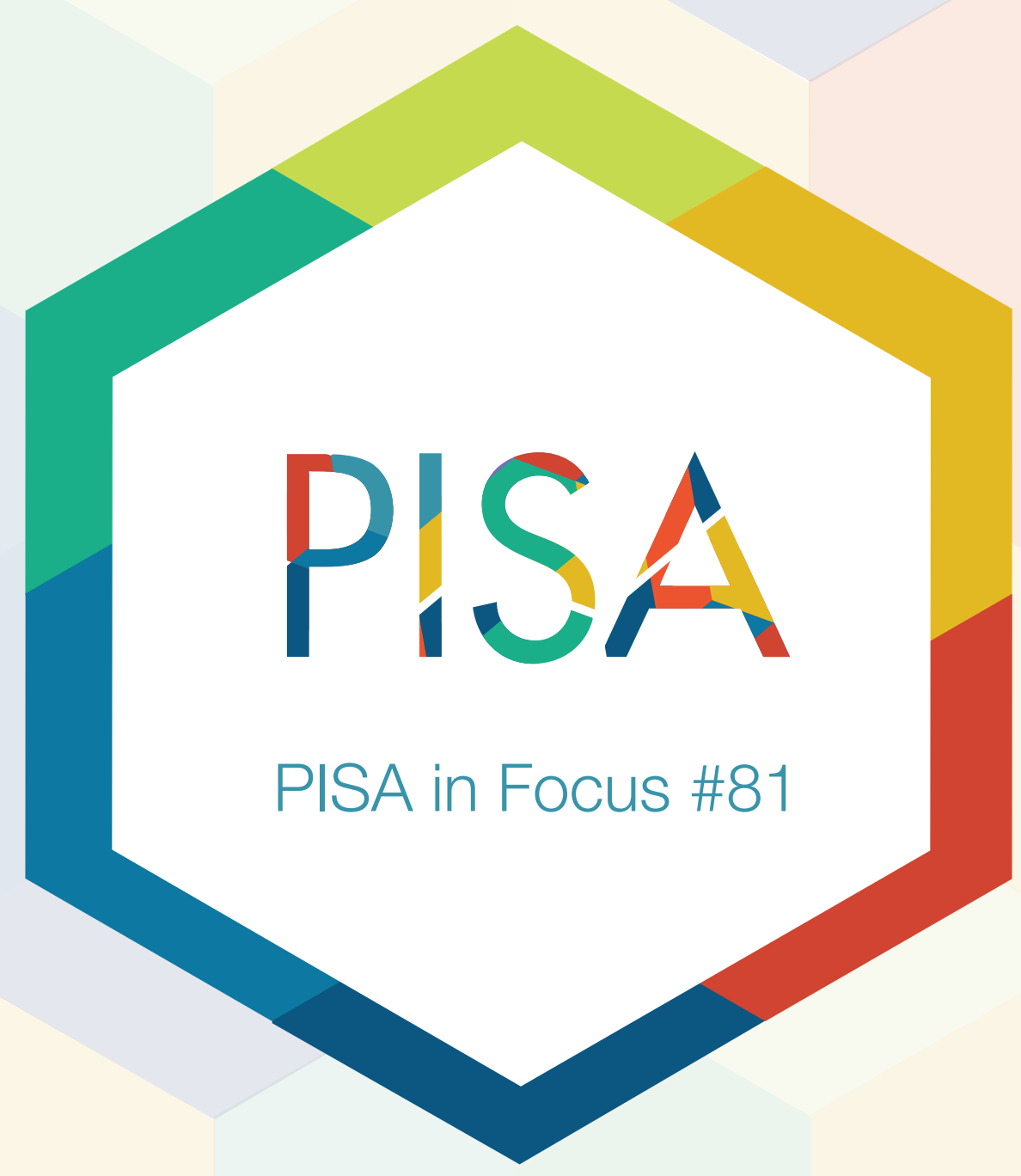




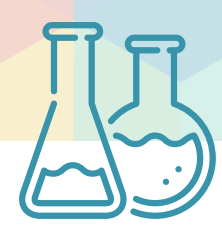

\section{What do science teachers find most satisfying about their work?}

- Science teachers who reported that their goal after completing secondary education was to become a teacher are more satisfied with their job and profession than those who reported that becoming a teacher was not their goal.

- Science teachers who collaborate with their colleagues and participate in professional-development activities are more satisfied than those who don't do either.

- The absence of noise and disorder in science classes is strongly associated with science teachers' satisfaction with their current job, while the composition of the student body in the school in terms of students' immigrant background and language is not.

Teachers play a vital role in the lives of their students. They impart knowledge, provide pastoral care, act as role models and, above all, create an environment that's conducive to learning. But teaching is fraught with numerous challenges that could lead to dissatisfaction; some teachers might decide to leave the profession entirely. In fact, in many countries around the world, high attrition rates are considered to be the most important factor contributing to the shortage of qualified science teachers.

So what is it that science teachers find satisfying about their work - satisfying enough that they want to keep teaching, despite any challenges they might face?

In 2015, and for the first time, PISA distributed an optional questionnaire to teachers of 15-year-old PISA students in 19 participating countries and economies. The questionnaire covered their working environment, teaching practices and their satisfaction with their current job and with the profession as a whole. The analyses of these data, in association with information about the students they teach and the schools in which they teach reveal some interesting findings.

\section{Science teachers who planned their career early on tend to be among the most satisfied.}

Science teachers who reported that pursuing a career in the teaching profession was their goal after finishing secondary school are more satisfied with their jobs and with the profession as a whole. For them, becoming a science teacher is a realisation of their long-held ambitions rather than an accident of the labour market. In fact, among the different factors examined in the analyses, achieving the goal of becoming a teacher is one of those most strongly associated with teacher satisfaction.

On average across all countries and economies, $58 \%$ of science teachers reported that their goal was to become a teacher after they finished secondary school. Those teachers were far more likely to be satisfied with their teaching profession and with their current job. The relationship is strong across most countries and economies, and particularly in Beijing-Shanghai-Jiangsu-Guangdong (China) (hereafter B-S-J-G [China]), Brazil, the Dominican Republic, Peru and the United Arab Emirates. 

accounting for science teachers' demographic profile ${ }^{1}$

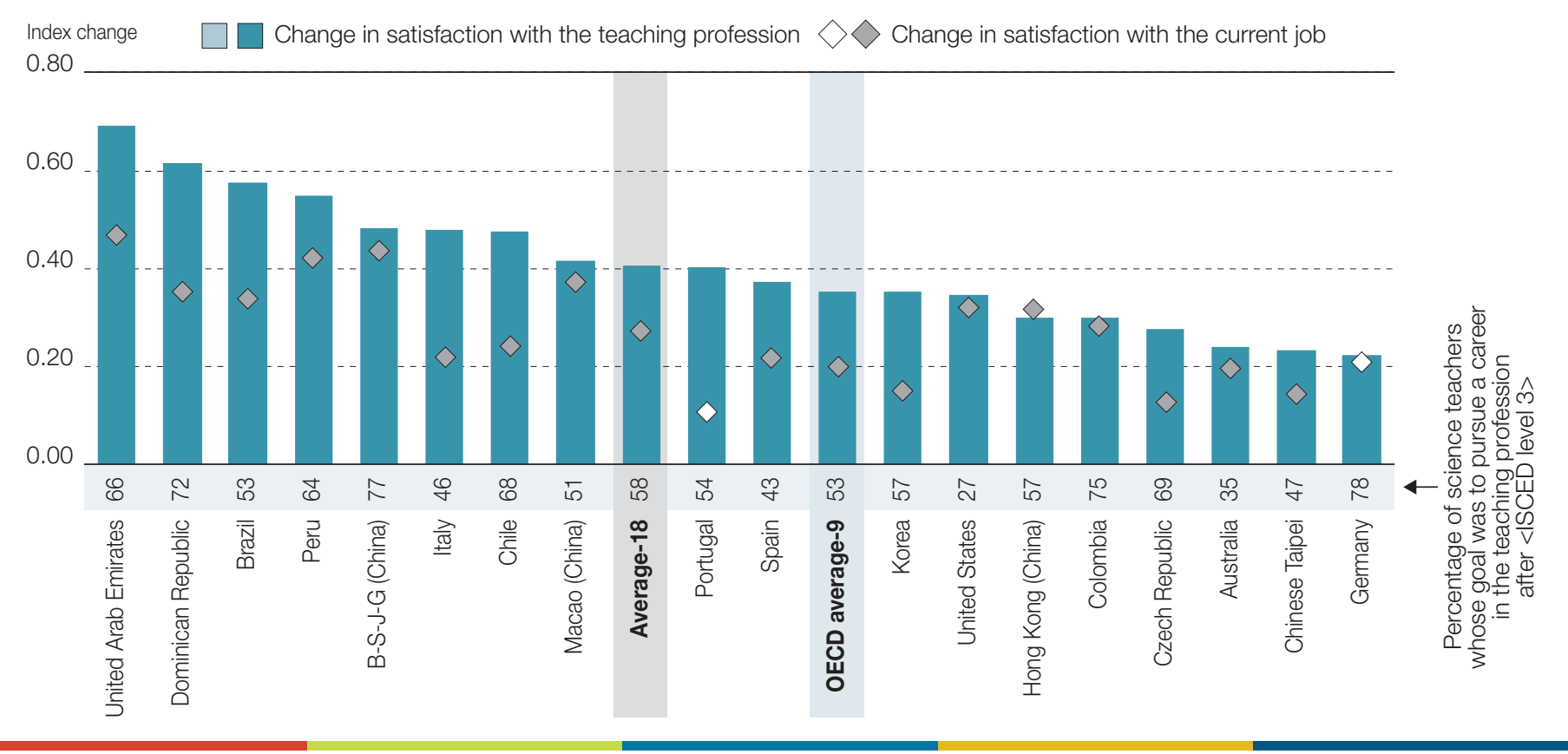

How to read this figure: This figure shows that, on average across the 18 countries/economies, $58 \%$ of science teachers of 15 -year-old students reported that their goal was to pursue a career in the teaching profession after completing high school (ISCED level 3 ). Teachers who so reported also had significantly higher levels of satisfaction with the teaching profession and with their current job than teachers who reported otherwise (as reflected in positive differences of 0.41 units and 0.27 units on the corresponding indices), after accounting for differences in teachers' demographic and schools'socio-economic profiles.

1. Science teachers' demographic profile includes the PISA index of economic, social and cultural status (ESCS) at the school level, science teachers' gender, total number of years working as a teacher, highest level of formal education completed, teacher education or training programme completed, and employment type at the current school.

Note: Statistically significant values are marked in a darker tone.

Countries and economies are ranked in descending order of the change in satisfaction with the teaching profession, after accounting for science teachers' demographic profile.

Source: OECD, PISA 2015 Database.

\section{Adequate school resources and a positive climate contribute to teachers' satisfaction with their job.}

Career motivation, in itself, is not sufficient if other factors are absent or if they undermine the learning process. For instance, the lack of educational or physical resources, and behavioural problems among students in school could undermine teachers' satisfaction.

Shortages of human and educational resources, as reported by teachers, are found to be negatively associated with teachers' satisfaction. For instance, teachers who perceive that the lack of teaching staff, or teachers being unprepared for class, hinders their schools' effectiveness tend to be less satisfied with their profession and with their current job. The difference in satisfaction between the teachers who reported that these shortfalls hinder their schools' effectiveness to a great extent and those who reported little or no impact on their schools' effectiveness are the largest in Australia, Brazil, Chile, Germany, Macao (China) and the United Arab Emirates. 


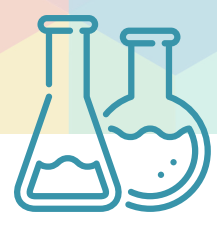

Views on staff shortage and satisfaction

Teacher satisfaction, by quarter of the index of science teachers' views on staff shortage

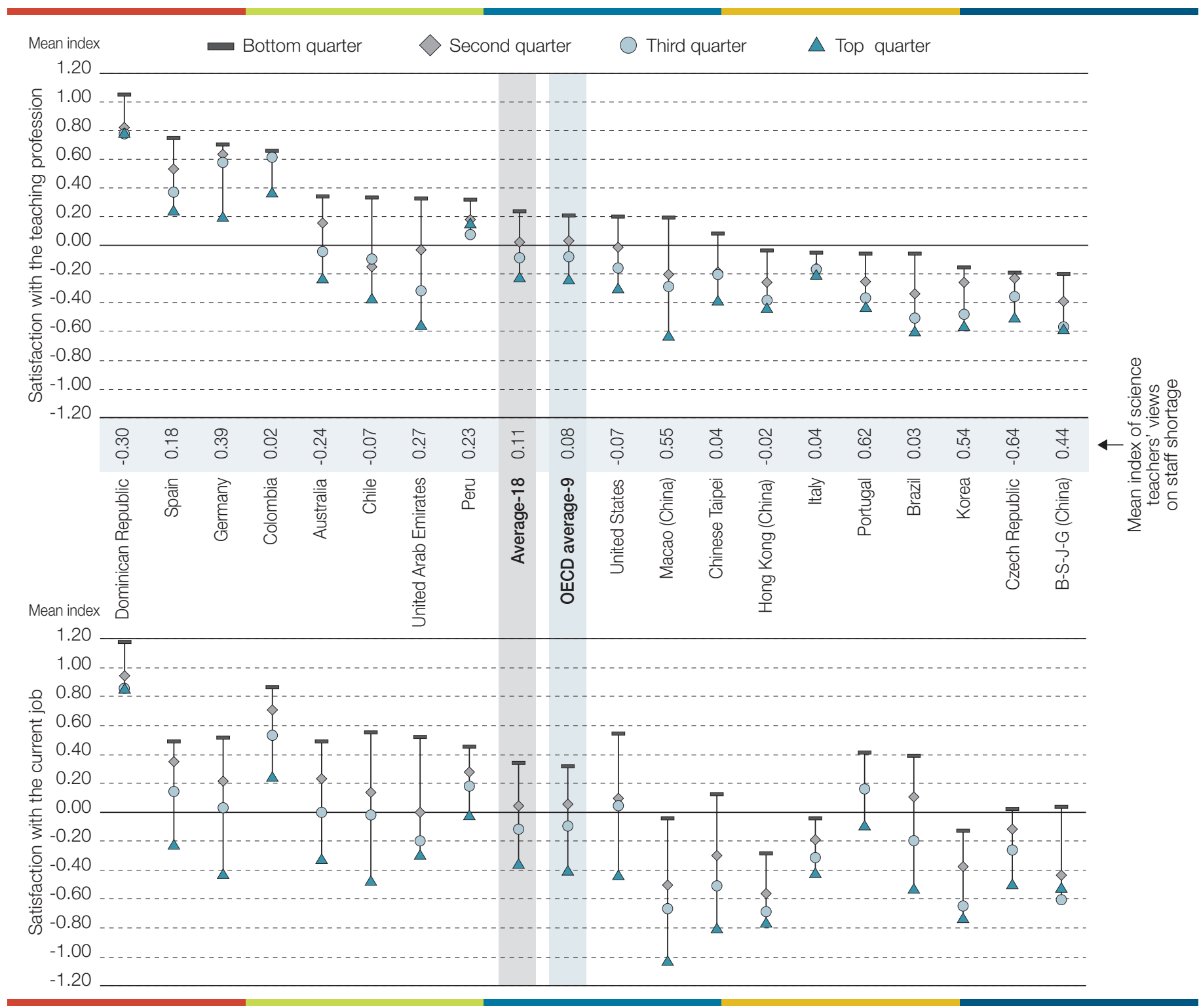

Countries and economies are ranked in descending order of satisfaction with the teaching profession among teachers in the bottom quarter of the index of science teachers' views on staff shortage.

Source: OECD, PISA 2015 Database.

The findings also show that in 10 out of 18 countries and economies, teachers' satisfaction with their current job is positively associated with the disciplinary climate in science class, as perceived by students, even after accounting for science teachers' demographic and schools' socio-economic profile. Across all participating countries and economies, an increase of one unit in the school average index of disciplinary climate in science lessons is associated with a rise of 0.24 points on the index of teacher satisfaction with the current job. The associations are particularly strong in Brazil, the Dominican Republic, Germany, Peru and the United States.

\section{A collaborative working environment is positively associated with teacher satisfaction.}

Teachers enjoy working in a collegial and supportive environment. Data from PISA 2015 show that collaborative activities among teachers are more common in Australia, B-S-J-G (China), Colombia, 
Disciplinary climate and science teachers' satisfaction with the current job Change in satisfaction with the current job associated with a one-unit change in student-reported index of disclipinary climate in science class at the school level

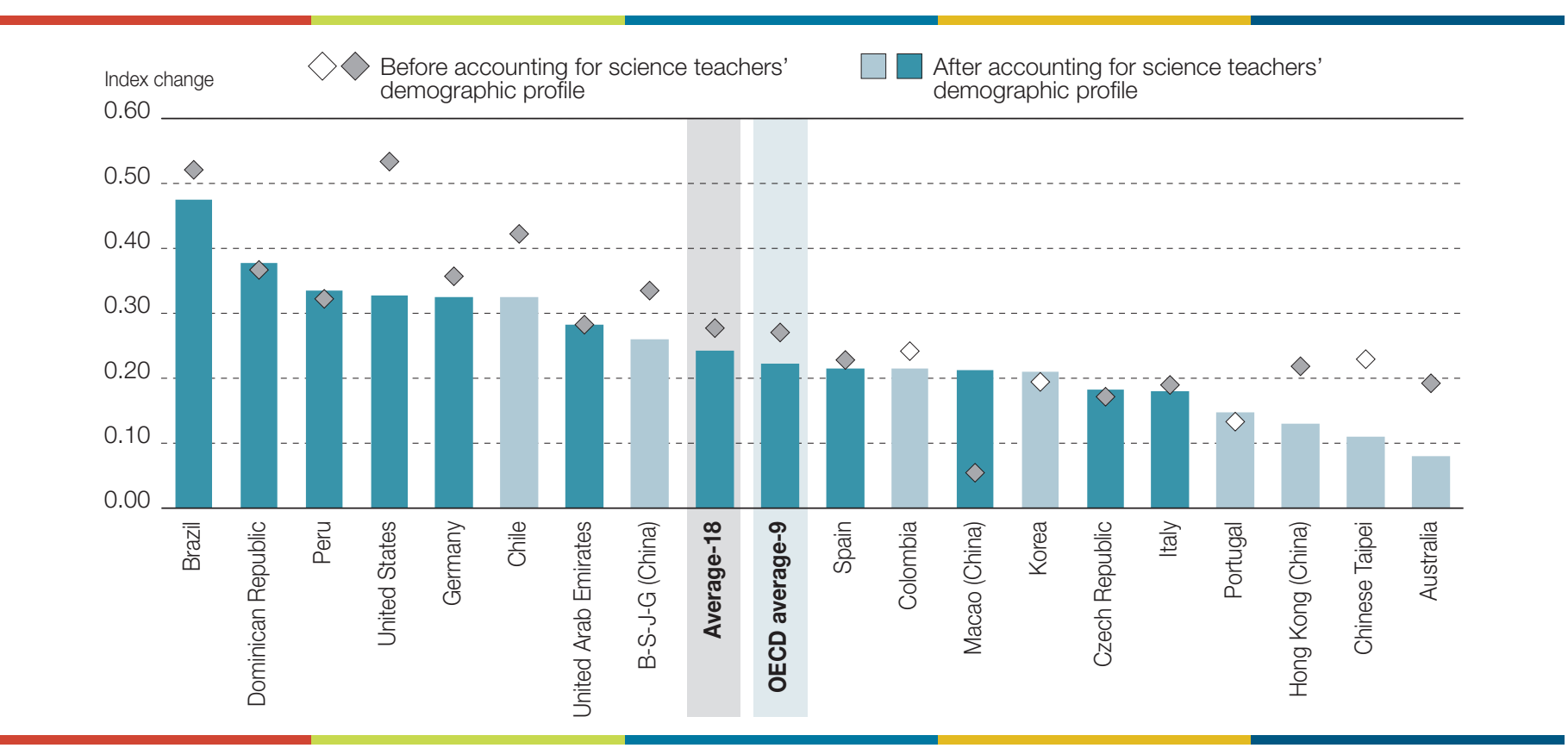

How to read this figure: See notes under Figure 1 "Pursuing a career in the teaching profession and satisfaction".

Notes: Science teachers' demographic profile includes the PISA index of economic, social and cultural status (ESCS) at the school level, science teachers' gender, total number of years working as a teacher, highest level of formal education completed, teacher education or training programme completed, and employment type at the current school.

The association with satisfaction with the profession is weaker.

Student variables are aggregated at the school level.

Statistically significant values are marked in a darker tone.

Countries and economies are ranked in descending order of the change in satisfaction with the current job, after accounting for science teachers' demographic profile.

Source: OECD, PISA 2015 Database.

the Dominican Republic, Korea, Macao (China), Peru, Portugal and the United Arab Emirates, and less common in Brazil, Chile, the Czech Republic, Germany, Italy and the United States. Teachers who reported frequent collaboration among their colleagues tend to be more satisfied with their job and with the profession as a whole. This association holds across all countries and economies, even though differences between the two groups of teachers vary in magnitude.

\section{Participation in professional-development activities is linked to teacher satisfaction, but the background of the students in the school is not.}

Most education systems offer professional-development opportunities to their teachers with the objective of improving their skills, something that could also contribute to their confidence and, ultimately, to their satisfaction as teachers. PISA 2015 shows that teachers in most countries engage in some professionaldevelopment activities. On average and across all countries, 52\% of teachers undertook more than three different types of professional-development activities during the preceding 12 months. The proportions are particularly large in B-S-J-G (China) (82\%), Brazil (65\%), the Dominican Republic (76\%), Peru (65\%) and the United Arab Emirates (65\%).

Science teachers who engaged in more than three types of professional-development activities during the preceding 12 months tend to be more satisfied with the teaching profession and with their current job. The impact is moderate in magnitude across the two measures of satisfaction. 


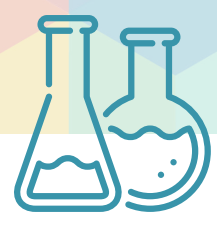

Science teachers' collaboration and satisfaction

Teacher satisfaction, by quarter of the index of science teacher's collaboration

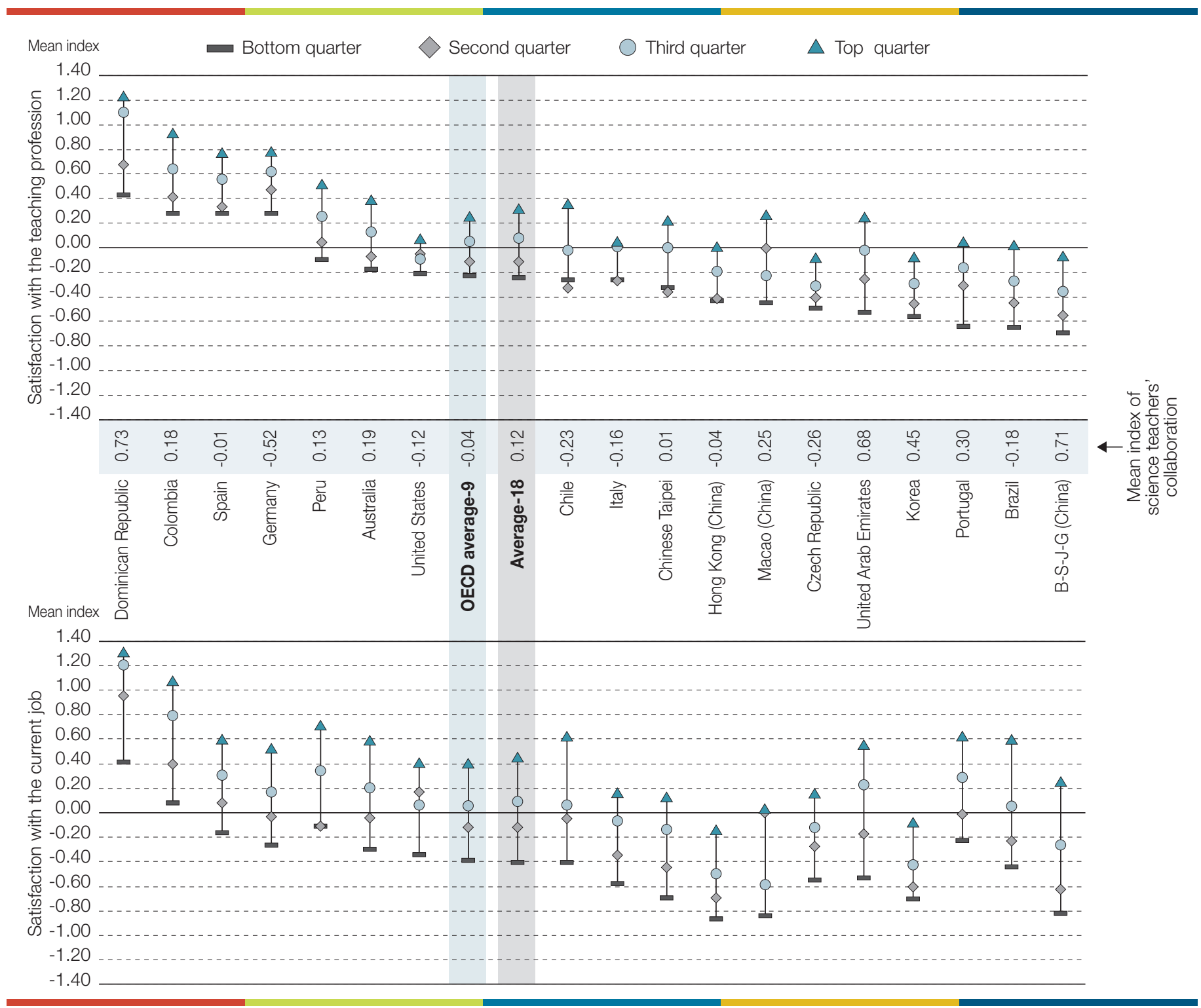

Countries and economies are ranked in descending order of satisfaction with the teaching profession among teachers in the bottom quarter of the index of science teachers' collaboration.

Source: OECD, PISA 2015 Database.

Some factors that are usually associated with challenging learning environments, such as the presence of large proportions of immigrant students or of students who do not speak the language of the host country, are not linked to teachers' dissatisfaction with their job or the profession. This finding is particularly interesting because it shows that teachers do not necessarily mind teaching in schools with more demanding student populations as long as the environment is conducive to learning, the school climate is positive, and adequate resources are available. This finding is encouraging because it shows that teacher satisfaction depends on aspects that policy could change. 
Science teachers' satisfaction with the teaching profession, by particpation in professionaldevelopment activities

Difference in satisfaction with the teaching profession between science teachers who participated in more than and those who participated in fewer than three professional acitivities during the previous 12 months

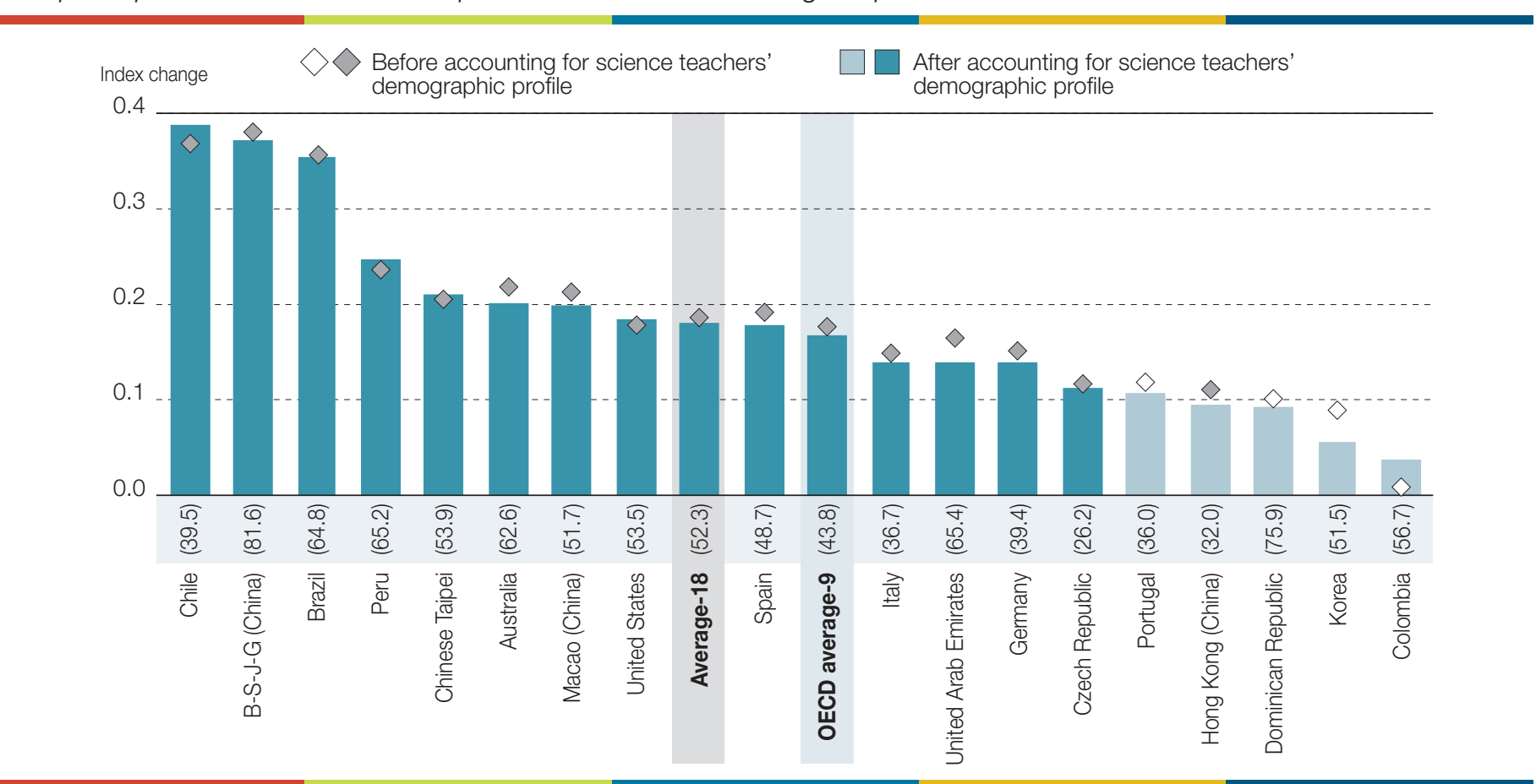

How to read this figure: See notes under Figure 1 "Pursuing a career in the teaching profession and satisfaction".

Notes: Science teachers' demographic profile includes science teachers' gender, total number of years working as a teacher, highest level of formal education completed, teacher education or training programme completed, and employment type at the current school.

Percentage of science teachers who participated in more than three professional-development activities during the previous 12 months are shown next to the country/economy name.

Statistically significant values are marked in a darker tone.

Countries and economies are ranked in descending order of the difference in satisfaction with the teaching profession between science teachers who participated in more than and those who participated in fewer than three professional-development acitivities during the previous 12 months, after accountig for science teachers' demographic profile.

Source: OECD, PISA 2015 Database.

\section{The bottom line}

Teacher satisfaction is positively associated with factors known to improve students' performance, such as collegial and positive school environments. In other words, teachers' satisfaction with their job and with the profession is both an aspect and a consequence of the school environment. As such, improving the learning experience for all students should also boost their teachers' professional satisfaction. 


\section{For more information}

Contact: Tarek Mostafa (Tarek.Mostafa@oecd.org)

See: Mostafa, T. and J. Pál, Science teachers' satisfaction: Evidence from the PISA 2015 teacher survey, OECD

Education Working Papers Series No. 168, http://dx.doi.org/10.1787/19939019.

Coming next month: How do language barriers affect immigrant students?

This paper is published under the responsibility of the Secretary-General of the OECD. The opinions expressed and the arguments employed herein do not necessarily reflect the official views of OECD member countries.

This document, as well as any data and map included herein, are without prejudice to the status of or sovereignty over any territory, to the delimitation of international frontiers and boundaries and to the name of any territory, city or area.

This work is available under the Creative Commons Attribution-NonCommercial-ShareAlike 3.0 IGO (CC BY-NC-SA 3.0 IGO). For specific information regarding the scope and terms of the licence as well as possible commercial use of this work or the use of PISA data please consult Terms and Conditions on www.oecd.org. 